\title{
Microbiological Criteria and Quality of Fruits and Fruit Juices in Ethiopia and International Experience
}

Hylemariam Mihiretie ${ }^{1,2 *}$ and Kassu Desta ${ }^{1}$

${ }^{1}$ Department of Medical Laboratory Sciences, College of Medical and Health Sciences, Wollega University, Nekemte, Ethiopia

${ }^{2}$ Department of Medical Laboratory Sciences, College of Medical and Health Sciences, Addis Ababa University, Addis Ababa, Ethiopia

\begin{abstract}
The consumption of fruits and fruit juices could have both positive and negative effect on the part of consumers. Fruits and fruit juices processed under hygienic condition could play important role in enhancing consumersâ health through inhibition of breast cancer, congestive heart failure (CHF), and urinary tract infection. In absence of good manufacturing practice; however, the nutritional richness of fruits and fruit juices makes the product good medium for microbial growth, vehicle of foodborne pathogens and associated complications. Although scanty on Ethiopian side, some countries of the world have set standards for the maximum permissible level of microbes in fruits, fruit juices and related products. The quality of fruits and juices is strictly maintained in developed countries under some law and regulation but in many developing countries where Ethiopia is not an exception; the manufacturer is not concerned about the microbiological safety and hygiene of fruits and juices because of negligence of law.
\end{abstract}

Keywords: Microbiological quality; Microbiological criteria; Fruits; Fruit juices

\section{Background}

Fruits and fruit juices are common beverages in many countries of the world. In hot climate areas, cafés, restaurants and road side stalls have local facilities to extract the juice from fresh fruits and then serving the juice liberally dozed with ice, to the thirsty customers [1].

The consumption of fruits and fruit juices could have both positive and negative effect on the part of consumers. Fruits and fruit juices processed under hygienic condition could play important role in enhancing consumers' health through inhibition of breast cancer, congestive heart failure $(\mathrm{CHF})$, and urinary tract infection. In absence of good manufacturing practice; however, the nutritional richness of fruits and fruit juices makes the product good medium for microbial growth, vehicle of foodborne pathogens and associated complications [2].

Fruits and juices contaminated at any point of processing could be the source of infectious pathogens. Study conducted on the microbiological safety of some fruit juices showed high prevalence of Salmonella in apple and orange juices. E. coli O157:H7 infection has been linked with consumption of apple juices. The prominent pathogens involved in unpasteurized juice outbreaks have been identified as $E$. coli O157:H7, Salmonella species and Cryptosporidium [3].

In recent years the increasing consumer awareness has emphasized the need for microbiologically safe food. Since the human food supply consists basically of animal and plant products, it is undesirable that our food supply can contain microorganisms in interaction with the food. When the microorganisms involved are pathogenic, their association with our food is critical from a public health point of view. Serious health hazards due to presence of pathogenic microbes in food can lead to food poisoning outbreaks [4].

Although scanty on Ethiopian side, some countries of the world have set standards for the maximum permissible level of microbes in fruits, fruit juices and related products [1].

\section{Microbiological Quality and Criteria Related Issues}

Worldwide, health concern has led to the popularization of natural fruit and fruit juice as a healthy alternative to other beverages. Fruits and fruit juices are nutritious which offer great taste and health benefits. The spoilage of food is most after due to contamination with aerobic acid-tolerant bacteria as well as yeasts and molds. Thus, enumeration of these microorganisms is an important aspect of evaluating the microbiology quality of acidic foods [4].

Most countries now have food regulations and enforcement mechanisms that prevent bacterial contamination of fruits and juices. Despite these efforts, another serious safety problem associated with fruits and juice consumption has arisen. Contaminations of fruits and juices with pathogenic microorganisms such as E. coli $\mathrm{O} 157 \mathrm{H} 7$ and salmonella have caused numerous illnesses and some fatalities. All reported cases of contamination by pathogenic microorganisms were due to fresh, unpasteurized juices and fruits. This is an increasingly popular segment of the juice industry, whose sales are now jeopardized by new regulations [5].

Microorganisms form part of the epiphytic flora of fruits and juices. This means that they grow on plants but are not parasitic to them, and thus many will be present at the time of consumption. The numbers of bacteria present will vary depending on seasonal and climatic variation with populations of $10^{5}$ to $10^{7} \mathrm{CFU}$ (colony forming units). The majority of bacteria found on the surface of plants is usually Gram negative and belong to the Pseudomonas group or to the family Enterobacteriaceae. There are many points during production of fruits and vegetables at which microbiological contamination can occur. These include: Growing (seeds, soil, water, manure, insects, and animals), Harvesting

*Corresponding author: Hylemariam Mihiretie, Department of Medical Laboratory Sciences, College of Medical and Health Sciences, Wollega University, Nekemte, Addis Ababa University, Addis Ababa, Ethiopia, Tel: 251576617 981; E-mail: hylemariam@gmail.com

Received October 08, 2015; Accepted November 13, 2015; Published November 16, 2015

Citation: Mihiretie H, Desta K (2015) Microbiological Criteria and Quality of Fruits and Fruit Juices in Ethiopia and International Experience. J Med Microb Diagn 4: 207. doi:10.4172/2161-0703.1000207

Copyright: (c) 2015 Mihiretie $\mathrm{H}$, et al. This is an open-access article distributed under the terms of the Creative Commons Attribution License, which permits unrestricted use, distribution, and reproduction in any medium, provided the original author and source are credited. 
(feces, handling, equipment, and transport), and Post-harvest handling (washing, packing, vehicles, cross-contamination). From a human health perspective, contamination of pathogens from human or animal sources is likely to present the greatest risk [6].

\section{Microbiological Criteria}

An important current trend is toward the use of procedures that deliver fruit and juice products are less "heavily" preserved, higher in quality, perceived as being more "natural", contain fewer additives, and are nutritionally healthier. Some new and "emerging" techniques aim to meet some of these objectives [7]. Microbiological criteria are intended to give some degree of assurance that food is safe and of suitable quality, and that it will remain so to the end of its shelf life provided it is handled appropriately. The EC Regulation on Microbiological Criteria for Foodstuffs requires Food Business Operators (FBO) to use the criteria given in the Regulation when carrying out validation and verification checks as part of food safety management systems based on Hazard Analysis and Critical Control Point (HACCP) principles [8].

Microbiological criteria must indicate the food and stage of processing to which they relate. Ideally, they should give a description of the food, indicating key processing features and conditions under which the material should be stored and used. Such factors significantly influence the content and validity of a microbiological criterion. For example, a specification for frozen food may allow higher aerobic plate counts at the point of production compared with the same chilled food since bacteria will not grow under frozen conditions but may grow during chilled storage. A microbiological criterion consists of a statement of at least the following: the microorganism or microbial toxin of concern, the food concerned and sample type, the sampling plan and the microbiological limit(s) [9].

In regulation EC/2073/2005 microbiological criteria are divided into two types namely: Food safety criteria - dealing with the presence of micro-organisms in the food, that represent a risk to human health, and Process hygiene criteria - dealing with microorganisms that can be used as indicators of the level of hygiene present in the food business. For Salmonella, as an important human pathogen, where five samples of $25 \mathrm{~g}$ each are taken none of the samples will contain detectable levels of Salmonella is acceptable. For E. coli as an indicator of process hygiene the following apply: Satisfactory if all values observed are less than $100 \mathrm{CFU} / \mathrm{g}$, acceptable if a maximum of microbes are between 100 and $1000 \mathrm{CFU} / \mathrm{g}$ and the rest of the values are less than $100 \mathrm{CFU} / \mathrm{g}$, unsatisfactory if one or more values observed are greater than $1000 \mathrm{CFU} / \mathrm{g}$ or more [10].

According to EC/2073/2005, the microbiological criteria of fresh fruits and juices include; regular testing against the criterion is not useful in normal circumstances for fresh, uncut and unprocessed vegetables and fruits, excluding sprouted seeds, Escherichia coli and Salmonella tests for pre-cut fruit and vegetables (ready-to eat) and unpasteurized fruit and juices should be performed, Salmonella tests for sprouted seeds [11].

\section{Microbiological Quality}

The quality of fruits and juices is strictly maintained in developed countries under some law and regulation but in many developing countries where Ethiopia is not an exception; the manufacturer is not concerned about the microbiological safety and hygiene of fruits and juices because of negligence of law. Thus the transmission of some human diseases through juice and other drinks are considered a serious problem in recent years [12].
Fruit juices may in fact consist of pathogenic microorganisms and the development of standards for fruit juices should be incorporated into most country's regulatory codes. Analyses can readily detect trace amounts of pesticides, industrial chemicals and vanishing low numbers of pathogens, some with "zero" tolerance levels. Thus there has been a substantial increase in import denials and product recalls based on levels of contaminants, microbial and chemical, that were undetectable and unimportant a decade ago. The economic loss, not to mention the liability and poor publicity, is adequate incentive for juice processors to consistently take regulatory matters very seriously [5].

Most fruits and fruit juices contain sufficient nutrients that could support microbial growth. Several factors encourage, prevent, or limit the growth of microorganisms in juices; the most important are aw, $\mathrm{pH}$, hygienic practice and storage temperature and concentration of preservative. Storage of products at refrigerator temperature or bellow is not always best for the maintenance of desirable quality of some fruits. Water used for juice preparation can be a major source of microbial contaminants such as total coliforms, fecal coliforms, fecal streptococci, etc. Environmental fomites may also make the fruits unsafe and these may have a role in spreading of Salmonella, Shigella, Vibrio, Escherichia coli, and other diseases causing as well as fruits spoilage types. Spoilage yeasts, such as Saccharomyces cerevisiae, Candida lipolytica and Zygosaccharomyces spp. can tolerate acidic environments. It should also be noted that changes in $\mathrm{pH}$ could transform a food into one, which can support growth of pathogens [13].

Fresh fruits and fruit juices, which have always been considered as healthful foods, may not always be safe owing to the heavy load of microbes. In a situation where storage of juice is indispensable may be for a short duration, then the use of simple processing techniques soon after its extraction is essential for improving the keeping quality to ensure its safety, nutritive quality and acceptability while consumption. Preservation of fruit juice by pasteurization, refrigeration and sterilization are popular methods used to attain microbiological stability by destroying pathogenic microorganisms and to preserve the color, aroma and taste of fresh juice [14].

The low $\mathrm{pH}$ of fruit juices greatly limits the number and types of bacteria that can survive or grow. Storage of products at refrigerator temperature or below is not always best for the maintenance of desirable quality of some fruits. Water used for juice preparation can be a major source of microbial contaminants such as coliforms, fecal coliforms, fecal streptococci, etc. [15].

\section{Experiences from the Local and the International Aspect}

In countries, where street food vending is prevalent, there is commonly lack of information on the incidence of food borne diseases related to the street vended foods. However, microbial studies on such foods in American, Asian and African countries have revealed increased bacterial pathogens in the food. There have been documented outbreaks of illnesses in humans associated with the consumption of unpasteurized fruit and vegetable juices and fresh produce. A report published by Victorian Government Department of Human services, Australia (2005) reported survival of E. coli 0157:H7 in apple juice for up to 24 days at $4^{\circ} \mathrm{C}$. A total of 48 cases of $E$. coli $0157: H 7$ were reported after drinking unpasteurized apple juice in Washington DC in 1996. Listeria monocytogenes has also been identified as a pathogen that is of concern in relation to these products [16].

Control of 5-HMF in apple juice in Serbia is obligatory from 2010, since the older legislation (“Službeni list SRJ", br. 33/95) did not 
prescribe control. In accordance with the official legislation ("Službeni glasnik RS", 27/10) $20 \mathrm{mg} / \mathrm{kg}$ is allowed limits for 5-HMF in apple juice. The International Federation of Fruit Juice Processors (IFFJP) has recommended maximum concentrations of $5-10 \mathrm{mg} / \mathrm{l}$ and $25 \mathrm{mg} / \mathrm{kg}$ in fruit juices and concentrates, respectively (Wagner, 2006); and the European Union has set a limit of $20 \mathrm{mg} / \mathrm{kg} 5$-HMF for juices made for children (FPA, 2006).

According to the U.S Food and Drug Administration, fruit and juice supply requires a comprehensive and coordinated effort throughout the fruit and juice production and transportation system. The responsibility to safeguard the fruit and juice supply is shared by everyone involved, from the grower to the consumer. This includes growers, farm workers, packers, shippers, transporters, importers, wholesalers, retailers, government agencies, and consumers. Analyzing the risk of microbial contamination includes a review of five major areas of concern. These involve: 1) water quality, 2) manure/municipal bio solids, 3) worker hygiene, 4) field, facility, and transport sanitation, and 5) trace back. Growers, processors, packers, and shippers should consider the variety of physical characteristics of produce and practices that affect the potential sources of microbial contamination associated with their operation, and decide on which combination of good agricultural and management practices are most cost effective [17].

The FDA also gives directions to reject fruits and juices which are not compatible with labeling requirements, spoiled, with prohibited additives, non-compliance with requirements of the U.S. low acid canned food regulations, heavy metal contamination, excessive levels of pesticide residues, and excessive levels of mycotoxin, mold infestation and microbiological contamination [18].

According to Ethiopian Public Health Institute (EPHI) food microbiology guideline, no person shall sell or consume fruits or juices that; is assumed to have any poisonous or harmful substance, unfit for human consumption, consists in whole or in part of any filthy, putrid, disgusting, rotten, decomposed or diseased fruits, spoiled, manufactured, prepared, preserved, packaged or stored under unsanitary conditions. Further no person shall manufacture, prepare, preserve, package or store for sale any fruit or fruit juices under unsanitary conditions [19].

\section{Laboratory Aspects}

Different parameters can be undertaken to evaluate the safety level of fruits and fruit juices [20]. Most probable number tests, microscopic examination, colony characteristics and rapid biochemical tests are some of the tests [21,22]. Microscopic investigation for Gram reaction and morphological features of suspected colony is also an important technique for screening the Gram reaction of bacteria [23,24].

Other tests like total viable count using serial dilution and total coliform count can also be performed. In total viable count serial decimal dilutions of each sample are made using peptone water solution as diluent. As a guide, with clean products dilution to $10^{-3}$ may be sufficient whereas heavily contaminated products may require dilution to $10^{-6}[23]$.

\section{Conclusion}

Several pathogenic bacteria, fungi and parasites capable of causing human disease can be found on raw fruits and fruit juices. Some of these microorganisms are capable of growing on whole, minimally processed or cut fruits and juices under routine handling and storage conditions. Differences in surface characteristics of fruits and juices, type and physiological state of microbial cells, and environmental stress conditions interact to influence the activity of disinfectants and sanitizers. Generally speaking, there are not microbiological standards and regulations which apply for the criteria and quality of fruits and fruit juices in Ethiopia and fruits and juices are sold in street market and supermarkets and no safe handling, processing and feeding except washing with water. Therefore there should be continual training and inspection of fruit growers and juice handlers at all levels in order to control microbiological hazards that may be influenced by current and changing aquaculture, agronomic, processing, distribution and preparation practices (Table 1).

\section{Acknowledgments}

The authors would like to acknowledge Addis Ababa University who contribute for the reality of this review.

\section{Conflict of Interest}

The authors declare that they do not have conflict regarding the publication of this review.

\section{References}

1. Al-jedah JH, Robinson RK (2002) Nutritional value and microbiological safety of fresh fruit juices sold through retail outlets in Qatar. Pakistan. J Nutr 1: 79-81.

2. Dennison BA (1996) Fruit juice consumption by infants and children: a review J Am Clin Nutr 15: 45-115.

3. Burnett SL, Beuchat LR (2001) Human Pathogens associated with raw produce and unpasteurized juices, and difficulties in contamination. $\mathrm{J}$ Indust Microbiol Biotechno 27: 104-110

4. Bagnde NI, Tumane PM (2011) Studies on microbial flora of fruit juices and soft drinks. Asiatic Journal of Biotechnology Resources 2: 454-460.

5. Bates RP, Morris JR, Crandall PG (2001) Principles and Practices of small and medium scale fruit juice processing. FAO Agricultural Services Bulletin 146: 1-221.

\begin{tabular}{|l|c|c|c|c|}
\hline Country & Year of publication & Authors & $\begin{array}{c}\text { Reference } \\
\text { number }\end{array}$ & Major findings \\
\hline India & 2009 & Tamberker et al. & {$[20]$} & Fruit and fruit juice related outbreaks of gastroenteritis caused by pathogenic E. coli, \\
Salmonella and Shigella are common
\end{tabular}

Table 1: Summary of experiences from various researches on microbiological aspects of fruits and fruit juices. 
Citation: Mihiretie H, Desta K (2015) Microbiological Criteria and Quality of Fruits and Fruit Juices in Ethiopia and International Experience. J Med Microb Diagn 4: 207. doi:10.4172/2161-0703.1000207

6. (2007) A Review of the fruit and Vegetable food Chain. Safe Food 1-103.

7. Lee SY (2004) Microbial Safety of Pickled Fruits and Vegetables and Hurdle Technology. Internet Journal of Food Safety 4: 21-32

8. (2006) Chilled Food Association (CFA), Guidance on the Practical Implementation of the EC Regulation on Microbiological Criteria for Foodstuffs 1: $1-52$.

9. Stanard C (1997) Development and use of microbiological criteria for foods. Food Science and Technology Today 11: 137-176.

10. Graftman A (2006) EU requirements for imports of fresh fruit and vegetables: a supplier's guide. 1: 1-50.

11. (2007) Cal-Med Consortium Workshop III, EU requirements for fresh Fruit and Vegetables.

12. Hossain A, Rahman M, Shabuz ZR (2012) Quality of Industrially Processed Fruit Juices: An Assessment Using Multivariate Framework. Dhaka Univ J Sci 60: 169-173.

13. Basar A, Rahman RS (2007) Assessment of Microbiological Quality of Processed Fruit Juice. Bangladesh J Microbiol 24: 166-168.

14. Rahman T, Hasan S, Noor R (2011) An Assessment of Microbiological Quality of Some Commercially Packed and Fresh Fruit Juice Available in Dhaka City: A Comparative Study. Stamford Journal of Microbiology 1: 13-18.

15. Braide W, Oranusi, SU, Otali CC (2012) Microbiological status of processed fruit juice sold in the commercial city of Onitsha. Scholarly Journal of Biological Science 1: 25-30.
16. Mahale DP, Khade RG, Vaidya VK (2008) Microbiological Analysis of Street Vended Fruit Juices from Mumbai City, India. Internet Journal of Food Safety 10: 31-34.

17. (1998) U.S. Department of Health and Human Services Food and Drug Administration Center for Food Safety and Applied Nutrition (CFSAN). Guide to Minimize Microbial Food Safety Hazards for Fresh Fruits and Vegetables

18. (2000) HACCP, Quality Control/Quality Assurance and International Trade Good Manufactug.P.G Practices (Gmp). Hygiene Requirements

19. Kiiyukia C (2003) UNIDO Project, Laboratory Manual of Food Microbiology for Ethiopia Health and Nutrition Research Institute. YA/ETH/03/436/11-52.

20. Tamberker DP, Jaiswal VJ, Dhanorker DV, Gulhane PB, Dudhane MN (2009) Microbial Quality and safety of street vended fruit juices: A case study of Amravati city. Internet Journal of Food Safety 10: 72-76.

21. Oranusi US, Wesley B (2012) Microbiological Safety Assessment of Apple Fruits (Malus domestica Borkh) Sold in Owerri Imo State Nigeria. Advance Journal of Food Science and Technology 4: 97-102.

22. Ketema T, Gaddisa T, Bacha K (2008) Microbiological Safety of Fruit Juices Served in Cafes/Resturants, Jimma Town, Southwest Ethiopia. Ethiop J Health Sci 18: $95-100$

23. Worku M (2011) Bacteriological Profile of Locally Prepared Fresh Fruit Juices in Hawassa Town, Southern Ethiopia. Thesis

24. Reddy B, Chandrakanth N, Indu S (2009) Isolation and Characterization of Fecal Coliforms in Street Vended Fruit Juices and Its Safety Evaluation: A Case Study of Bellary City, India. Internet Journal of Food Safety 11: 35-53. 